\title{
Hepatic artery aneurysm
}

\author{
F.T. Curran and S.A. Taylor \\ Department of Surgery, Royal Hospital, Wolverhampton, UK.
}

\begin{abstract}
Summary: We describe a 58 year old woman who had an aneurysm involving the common hepatic artery, the right and left hepatic arteries and the cystic artery which had ruptured into the liver. It was successfully treated by proximal ligation. The features and management of hepatic artery aneurysm are discussed.
\end{abstract}

\section{Introduction}

Although rarely seen, aneurysm of the hepatic artery is the second most common visceral aneurysm. Diagnosis is difficult and the mortality may be as high as $80 \%$ (Ariyan et al., 1975; Countryman et al., 1983; Guida \& Moore, 1966). However, current evidence suggests that repair of these aneurysms is unnecessary - a proximal tie being all that is required. This knowledge, together with advances in diagnosis, should considerably improve the survival of patients with hepatic artery aneurysm.

\section{Case report}

A 58 year old woman was admitted with a 5 day history of fever, dry cough, a rigor and pleuritic chest pain. She was known to have had chronic lymphatic leukaemia for 20 years and this was associated with a secondary hypogammaglobulinaemia.

On examination she was pyrexial and tachypnoeic. The right lower zone of her chest was dull to percussion. Her abdomen was not tender and no masses were palpable. A diagnosis of lobar pneumonia was made.

Chest X-ray revealed a large right pleural effusion and possibly consolidation of the lower lobe of her right lung. An electrocardiogram was normal. Treatment with erythromycin $500 \mathrm{mg}$ q.d.s. was given.

Over the next few days she became jaundiced and liver function tests showed an obstructive pattern. Ultrasound examination of her abdomen showed a cystic lesion, $6 \mathrm{~cm}$ in diameter at the porta hepatis lying between the common bile duct and the portal vein and extending into the right lobe of the liver. The biliary tree was dilated. A computed tomographic scan gave no additional information. In view of the above

Correspondence: F.T. Curran, F.R.C.S., Department of Surgery, Selly Oak Hospital, Raddlebarn Road, Birmingham B29 6JD, UK.

Accepted: 10 April 1986 history, a diagnosis of hepatic abscess was thought most likely. An attempt was made to aspirate the contents under X-ray control; this produced $150 \mathrm{ml}$ of altered blood.

At laparotomy the findings were a large aneurysm of the common hepatic artery and the right and left hepatic arteries commencing at the origin of the gastroduodenal artery. It extended along the cystic artery and into the gallbladder, which was ischaemic. The aneurysm had ruptured into the liver and was compressing and displacing the common bile duct and hepatic ducts. There was a large haematoma in the right lobe of the liver and the liver capsule had been stripped on the diaphragmatic surface. The hepatic artery was ligated proximal to the origin of the gastroduodenal artery, and this resulted in collapse of the aneurysm. Cholecystectomy was performed and the damaged liver surface was covered with an omental patch.

Post-operative recovery was slow and the patient spent over two months in hospital. The problems of note were an intitial deepening of her jaundice which faded over several weeks; an Escherichia coli septicaemia which responded to cephalosporin antibiotics, and a biliary fistula at the drain site. However, by the time of her discharge from hospital she was feeling well, her liver function tests were normal apart from a slightly raised alkaline phosphatase and the biliary fistula was draining only a few mls a day. At review two months later the fistula was closed, she was symptom-free and there were no abdominal signs.

\section{Discussion}

The first known case of hepatic artery aneurysm was reported in 1819 by Wilson. The patient was a 50 year old man, who died in 1809 from rupture of an aneurysm of the left hepatic artery and the diagnosis was made at post-mortem examination (Rolland, 
1908). The first successful treatment of an hepatic artery aneurysm was by $\mathrm{Kehr}$ in 1903; he ligated and divided an aneurysm of the common hepatic artery which had ruptured into the gallbladder. There are now more than 300 cases reported but only $20 \%$ have been successfully treated (Countryman et al., 1983; Ariyan et al., 1975; Guida \& Moore, 1966).

Hepatic artery aneurysms constitute $20 \%$ of visceral aneurysms and only those of the splenic artery are more common. The precise mechanism leading to the formation of the aneurysm is uncertain but atherosclerosis is an associated factor in $32 \%$ of patients and acquired degeneration of the media is found in a further $24 \%$. Whereas at the turn of the century nearly all hepatic artery aneurysms were due to mycotic lesions, they now account for only $10 \%$ of cases (Rutherford, 1977). Trauma, including iatrogenic trauma occurring during biliary surgery, may be the cause of $22 \%$. Less common causes are syphilis, tuberculosis, polyarteritis nodosa and cholecystitis (Guida \& Moore, 1966).

Twenty per cent of hepatic artery aneurysms are intrahepatic and are usually false aneurysms following trauma. The remaining $80 \%$ are extrahepatic. Guida $\&$ Moore (1966), in their review of 170 patients, found the anatomical distribution of the extrahepatic aneurysms to be as follows: common hepatic artery $64 \%$, right hepatic artery $30 \%$, left hepatic artery $4 \%$ and both left and right hepatic arteries $2 \%$. The age distribution was $10-83$ years, mean 38 years. Males were affected twice as often as females.

The clinical features tend to be non-specific. Most patients complain of upper abdominal pain not related to food, and physical signs are rare, though one may find a mass, hepatomegaly or a bruit. Eighty per cent are not detected until haemorrhage occurs. Rupture occurs most often into the peritoneal cavity $(43 \%)$ and this is usually rapidly fatal; $41 \%$ rupture into the gallbladder or bile ducts (Truman-Mays, 1977). The resulting haemobilia is characterized by Quincke's triad of symptoms, viz. biliary colic, gastro-intestinal haemorrhage and obstructive jaundice (Harlaftis \& Akin, 1977). Eleven per cent rupture into the stomach or duodenum and $5 \%$ into the portal vein (Guida \& Moore, 1966; McKinnon et al., 1981). The latter may be followed by portal hypertension and varices (Wheeler \& Warran, 1957). Hepatic artery aneurysms following biliary surgery have been known to present with haemorrhage from T-tubes (Quattelbaum, 1954).

The diagnosis of hepatic artery aneurysm is difficult to make, usually requiring a high index of clinical suspicion and angiography (Cohen et al., 1966; Countryman et al., 1983; Guida \& Moore, 1966; Shaw, 1982). Plain abdominal X-ray may reveal a ring of calcification in the upper abdomen and barium studies may show a deformed duodenum due to an extrinsic mass (Shaw, 1982). Ultrasound scan and CT scan will often detect the mass but, as in our patient, may not give sufficient information to make the diagnosis.

With regard to treatment, hepatic artery aneurysms have traditionally been divided into two groups those proximal to the gastroduodenal artery and those distal to it. It is generally accepted that a proximal aneurysm can be safely ligated with or without excision, without risk of liver necrosis. Arterial blood reaches the liver from the superior mesenteric artery via the inferior pancreatico-duodenal artery, superior pancreatico-duodenal artery, gastroduodenal artery and thence the hepatic arteries. This collateral pathway is not available if ligation is distal to the gastroduodenal artery, and over the years many methods have been devised to restore the flow of arterial blood to the liver. These are, as listed by Countryman et al. (1983), reconstructive endoaneurysmorrhaphy, excision with end-to-end anastomosis, excision with splenohepatic anastomosis, excision with saphenous vein graft reconstruction, excision with prosthetic graft reconstruction, suturing of aneurysm to the liver, wrapping of the aneurysm with cellophane, wiring of the aneurysm and hepatic lobectomy. However, there is evidence that ligation of the hepatic artery distal to the gastroduodenal artery in fact carries little risk of hepatic ischaemia because adequate oxygenation is provided by other collateral channels, aberrant vessels and increased extraction of oxygen from the portalo vein blood (Madding \& Kennedy, 1972).

Brittain et al. (1964) reported five patients in whom the common hepatic artery or right hepatic artery had been injured, and reviewed previous publications. They concluded that 'ligation of the hepatic artery or one of its branches in the patient with relatively normal hepatic function is not ordinarily fatal in the otherwise uncomplicated case.' This is supported by the fact that ligation of the hepatic artery is a recognized treatment for metastatic liver tumours and liver necrosis does not appear to occur (Murray-Lyon et al., 1970).

Michels (1960) in his dissection of 200 livers, found that the vessels conformed to the standard textbook description in only $55 \%$ of people. In the remaining $45 \%$ there were collateral vessels and he described 26 possible collateral pathways. Within four days of arterial flow being interrupted collateral flow occurs via phrenic and intercostal arteries, the opposite lobe and the falciform ligament (Madding \& Kennedy, 1972). In addition, splanchnic arteriovenous communications increase the blood flow through the portal vein and raise its oxygen concentration. Under normal conditions the portal vein supplies $50 \%$ of the liver's oxygen.

Selective percutaneous embolization using Gelfoam has been used in the treatment of hepatic artery aneurysms and the results appear to be encouraging. This procedure has the advantage that it can be 
performed under local anaesthetic and at the same time as the diagnosis is made at angiography (Goldblatt et al., 1977).

The treatment of choice for hepatic artery aneurysm, therefore, is simple proximal ligation or ligation with excision irrespective of whether the aneurysm is proximal or distal to the gastroduodenal artery. Simple measures such as avoiding hypotension or hypoxia, using fresh blood for transfusion and resting the bowel for a few days post-operatively should render the small possibility of liver necrosis even more remote. Selective embolization may prove to be a useful alternative treatment especially in a patient unfit for surgery.

\section{References}

ARIYAN, S., CAHOW, C.E., GREENE, F.L. \& STANSEL, M.C. (1975). Successful treatment of hepatic artery aneurysm with erosion into the common duct. Annals of Surgery, $182,169$.

BRITTAIN, R.S., MARCHIORO, T.L., HERMANN, G., WEDDELL, W.R. \& STARZL, T.E. (1964). Accidental hepatic artery ligation in humans. American Journal of Surgery, $107,822$.

COHEN, Y., CHOW, K.W. \& SEAH, C.S. (1966). Intrahepatic aneurysm pre-operatively diagnosed and treated by resection. British Journal of Surgery, 53, 602.

COUNTRYMAN, D., NORWOOD, S., REGISTER, D., TORMA, M. \& ANDRASSY, R. (1983). Hepatic artery aneurysm. Report of an unusual case and review of the literature. The American Surgeon, 49, 51.

GOLDBLATT, M., GOLDIN, A.R. \& SHAFF, M.I. (1977). Percutaneous embolisation for the management of hepatic artery aneurysm. Gastroenterology, 73, 1142.

GUIDA, P.M. \& MOORE, S.W. (1966). Aneurysm of the hepatic artery. Report of five cases with a brief review of the previously reported cases. Surgery, 60, 299.

HARLAFTIS, N.N. \& AKIN, J.T. (1977). Haemobilia from ruptured hepatic artery aneurysm; report of a case and a review of the literature. American Journal of Surgery, 133, 229.

KEHR, M. (1903). Der erste fall von erfologreicher unterbingung der arteria hepatica propria wegen aneurysma. Munchener Medizinische Wochenschrift, 2, 1861

MADDING, G.F. \& KENNEDY, P.A. (1972). Hepatic artery ligation. Surgical Clinics of North America, 52, 719.

McKINNON, W.M., SMITH, R.B., DAVIS, S.C., CONNELLY, T.L. \& PERDUE, G.D. (1981). Ruptured hepatic artery aneurysm with hepatic artery-to-portal vein fistula. Surgery, 89, 626.

MICHELS, N.A. (1960). Newer anatomy of the liver - variant blood supply and collateral circulation. Journal of the American Medical Association, 172, 125.

MURRAY-LYON, I.M., PARSONS, V.A., BLENDIS, L.M., DAWSON, J.L., RAKE, M.O., LAWS, J.W. \& WILLIAMS, R. (1970). Treatment of secondary hepatic tumours by ligation of the hepatic artery and infusion of cytotoxic drugs. Lancet, ii, 172.

QUATTELBAUM, J.K. (1954). Hepatic artery aneurysm; 3 cases. Annals of Surgery, 139, 743.

ROLLAND, W. (1908). Aneurysm of the hepatic artery; clinical and pathological notes of a case with a review of the previously reported cases. Glasgow Medical Journal, 69, 342.

RUTHERFORD, R.B. (1977). In Vascular Surgery, 1st edition, p. 676. W.B. Saunders: Philadelphia.

SHAW, J.F. (1982). Hepatic artery aneurysms. British Journal of Hospital Medicine, 28, 404.

TRUMAN-MAYS, E. (1977). Vascular occlusion. Surgical Clinics of North America, 57, 306.

WHEELER, H.B.\& WARREN, R. (1957). Duodenal varices due to portal hypertension from arteriovenous aneurysm. Annals of Surgery, 146, 229.

WILSON, J. (1819). In Lectures on the Blood and on the Anatomy, Physiology and Surgical Pathology of the Vascular System of the Human Body. p.379. Burgess \& Hill, London. 